\title{
Two Cases of Cryptococcal Meningitis, One Treated with 5-Fluorocytosine
}

\author{
J. S. WATKINS,* M.B., B.S. ; M. J. CAMPBELL, † M.B., M.R.C.P. ; D. GARDNER-MEDWIN, $\ddagger$ M.B., M.R.C.P. \\ H. R. INGHAM,§ M.B., M.C.PATH., DIP.BACT. ; I. G. MURRAY,\| M.B., M.C.PATH., D.T.M.\&H.
}

British Medical fournal, 1969, 3, 29-31

\begin{abstract}
Summary: Cryptococcal meningitis occurred in two patients in the North of England. One, an elderly woman who was ill for 12 months with an obscure indolent meningitis until use of steroid drugs resulted in an acute exacerbation during which cryptococci were isolated, was treated successfully with amphotericin B. The other, a student from New Guinea with subacute meningitis, could not tolerate amphotericin $B$ but responded to two courses of oral treatment with 5-fluorocytosine $100-200 \mathrm{mg}$. $/ \mathrm{kg}$./ day without any appreciable side-effects. Further trials of this drug in the treatment of cryptococcosis are recommended.
\end{abstract}

\section{Introduction}

Meningitis caused by Cryptococcus neoformans is rare in Britain and is known for its frequent association with debilitating disease and for the difficulties involved in its diagnosis and treatment. The two cases described showed no evidence of predisposing disease.

\section{Case 1}

A 64-year-old Newcastle housewife had for six months been feeling "shaky," especially when walking, and had tended to deviate to the left. Recently she had been excessively sleepy, increasingly deaf, and mildly dysarthric, and just before her admission she became depresssed and confused. She had lost $12.7 \mathrm{~kg}$. in weight. She denied headache, but had vomited repeatedly in the mornings. She was admitted to the department of psychological medicine, where examination of the cerebrospinal fluid (C.S.F.) showed evidence of a chronic meningitis; repeated searches for acid-fast bacilli and fungi, however, were negative.

She was transferred to the neurological unit with a provisional diagnosis of sarcoid meningitis. On examination she was thin and ill but apyrexial ; the chest, abdomen, and pelvis were normal. She was confused and disorientated in time and place, had bilateral anosmia and mild perceptive deafness but no other cranial nerve abnormalities, and the fundi were normal. Neck stiffness was absent. There was a fine tremor of the outstretched hands with brisk reflexes in all four limbs, absent abdominal reflexes, and bilateral extensor plantar responses. She remained depressed in spite of antidepressant therapy.

Investigations.-Blood count and E.S.R., blood urea, and serum proteins were all normal ; serum calcium was $8.7 \mathrm{mg} . / 100 \mathrm{ml}$., Wassermann reaction and Reiter protein complement fixation test were negative in blood and C.S.F. Repeated C.S.F. examinations showed white cell counts of $75-177 / \mathrm{cu}$. mm., predominantly pnlymorphs, sugar 15-18 mg./100 ml., and protein 150-180 mg./ $100 \mathrm{ml}$. No acid-fast bacilli, fungi, or viruses were found on repeated microscopical examination or culture of the fluid. An E.E.G. showed no focal abnormality. Radiographs of the chest, lumbar spine, hands, and skull, bilateral carotid angiograms, and

* Senior House Officer in Neurology, Regional Neurological Centre, Newcastle General Hospital, Newcastle upon Tyne.

t Research Fellow in Neurology, Regional Neurological Centre, Newcastle General Hospital, Newcastle upon Tyne.

‡ Senior Registrar in Neurology, Regional Neurological Centre, Newcastle General Hospital, Newcastle upon Tyne.

$\checkmark$ Senior Bacteriologist, Public Health Laboratory, Newcastle General Hospital.

|| Director, the Mycological Reference Laboratory, London School of Hygiene, London W.C.1. an air encephalogram were normal. Mantoux test $1 / 100$ was negative, as were the biopsy specimen from the scalene node and the Kveim test.

During several months in hospital the patient showed a gradual, spontaneous improvement; she became orientated and alert, her walking gradually improved, and she began to gain weight. Six months after her admission sarcoidosis was still thought to be the most likely diagnosis despite the negative investigations, and treatment was started with prednisone $30 \mathrm{mg}$. daily.

A week later she developed vomiting and pain in the neck and back of the head, and again became drowsy, confused, and dehydrated, with marked deafness and a spastic tetraparesis. The C.S.F. contained 24 white cells/cu. $\mathrm{mm}$ ( $90 \%$ polymorphs), protein $332 \mathrm{mg} . / 100 \mathrm{ml}$., and sugar $21 \mathrm{mg} . / 100 \mathrm{ml}$. On this occasion encapsulated yeasts were visible on Gram-stained smears and C. neoformans was cultured from the C.S.F. on two successive days. Serological tests for cryptococci were positive in blood (antigen titre $1 / 16$, antibody $1 / 8$ ) and C.S.F. (antigen titre $1 / 16$, antibody $1 / 4)$.

The steroids were withdrawn and she was started on intravenous and intrathecal amphotericin B in the recommended doses (see Discussion). After 10 days of treatment her clinical condition and the C.S.F. findings had improved and intrathecal medication was stopped. Intravenous infusions of amphotericin B were continued for 72 days. Her progress was complicated by perforation of a colonic diverticulum, requiring a temporary colostomy, and a postoperative pulmonary embolus. She received a total of $3,000 \mathrm{mg}$. of amphotericin B intravenously, and by the seventh week the C.S.F. had almost reverted to normal (C.S,F. protein $51 \mathrm{mg} . / 100 \mathrm{ml}$., sugar $41 \mathrm{mg} . / 100 \mathrm{ml}$.). She went home after a further four weeks, when her C.S.F. was normal and her blood and C.S.F. immunological tests for $C$. neoformans were negative. During the long period of treatment the blood urea was raised $(41-75 \mathrm{mg} . / 100 \mathrm{ml}$.) and she had persistent hypokalaemia requiring large doses of supplementary potassium salts.

Nine months after the completion of treatment she was still rather ataxic, but she felt well and was able to do her housework. Immunological tests for $C$. neoformans remained negative in serum and C.S.F.

\section{Case 2}

A 24-year-old male student from New Guinea, who had also travelled in Australia, had been in this country for one year. His previous health had been good, but two weeks before admission he had developed severe frontal headache, fever, and anorexia, which were followed after a week by pain in his neck and back, diplopia on lateral gaze, and unsteadiness when walking.

On admission to hospital he had a temperature of $37.2^{\circ} \mathrm{C}$. and signs of meningism. The visual acuity, visual fields, and fundi were normal. He had fine phasic nystagmus on lateral gaze and mild bilateral sixth nerve pareses but no other cranial nerve abnormality. There was no limb weakness, but all tendon reflexes were diminished and there was a mild truncal ataxia, Further examination was negative.

Investigations.-E.S.R. $64 \mathrm{~mm}$./hour (Westergren). A blood count and radiographs of skull and chest were normal. The C.S.F. was under high pressure and contained 125 white cells/cu. mm., mostly lymphocytes, protein $26 \mathrm{mg} . / 100 \mathrm{ml}$., and sugar $54 \mathrm{mg} . /$ $100 \mathrm{ml}$. Encapsulated yeasts were seen on direct microscopy and C. neoformans was later isolated on culture. Two days later the C.S.F. sugar fell to $40 \mathrm{mg} . / 100 \mathrm{ml}$. Agglutination tests for cryptococcal antigen and antibody were positive in serum and in C.S.F. in high titres. 
An infusion of amphotericin B was started and within four hours he became restless and confused, began to vomit, and had severe rigors with a rise of temperature to $40^{\circ} \mathrm{C}$. These symptoms recurred each day when the infusion was started but were minimized by large doses of promethazine.

A week after treatment was started he developed a mild right hemiparesis, right lower motor neurone facial paresis, slurring dysarthria, and coarse nystagmus in the adducting eye on looking to the left. Cryptococci were still being cultured from the C.S.F. It was thought that he had developed a basal meningitis and he was given intravenous hydrocortisone $50 \mathrm{mg}$. three times daily and intrathecal amphotericin B $0.05 \mathrm{mg}$. daily, gradually increased to $0.75 \mathrm{mg}$. daily, and then maintained at this level for 10 days despite severe headaches, backache, and incontinence of urine following its administration. Shortly after this all treatment with amphotericin B had to be stopped, as his blood urea rose to $90 \mathrm{mg} . / 100 \mathrm{ml}$. and remained so despite a reduction in the intravenous dose. He had received a total of only $350 \mathrm{mg}$. of the drug. Prednisone $30 \mathrm{mg}$. daily was continued and his symptoms improved. Though this was no doubt in part due to discontinuing the amphotericin $\mathrm{B}$, there was also by this time improvement in the serum cryptococcal agglutination titres. The C.S.F., however, was still abnormal (Fig. 1).

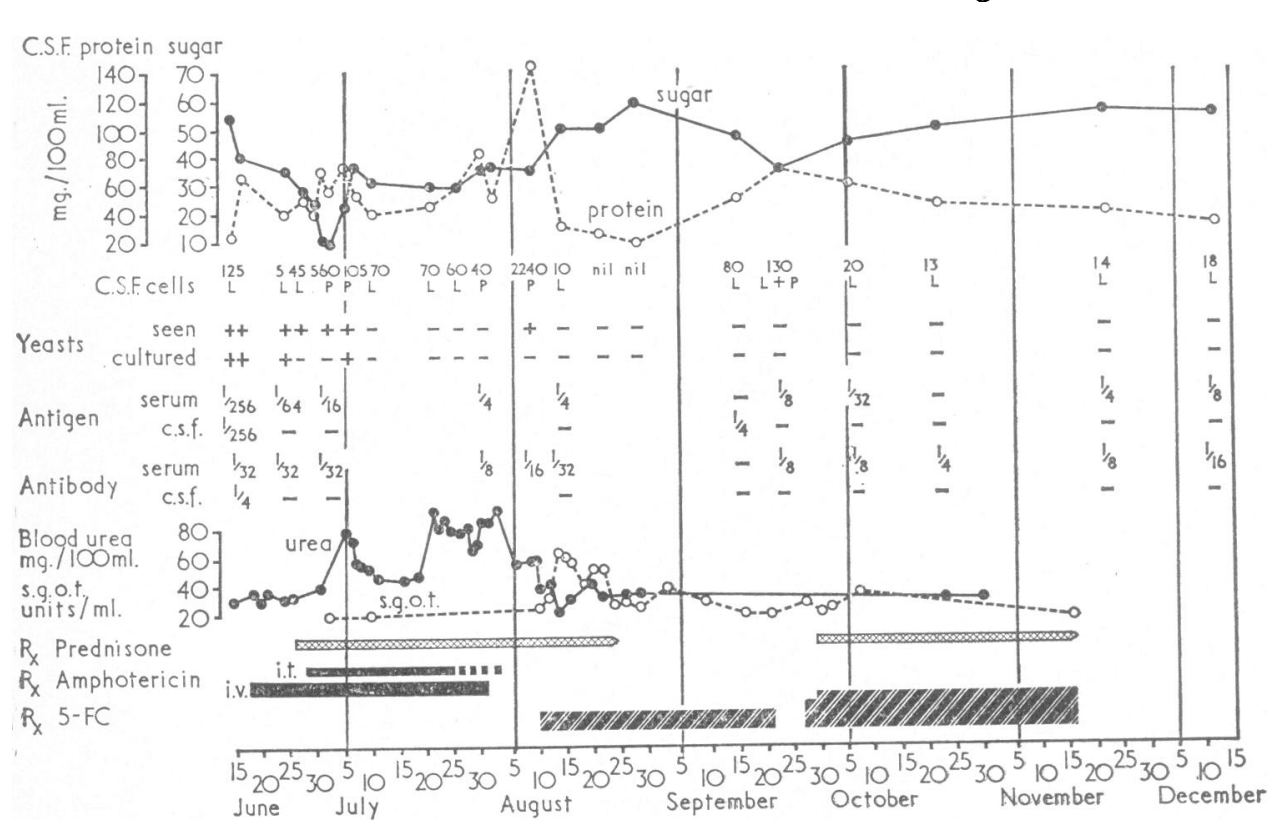

FIG. 1.-Case 2. Chart of laboratory findings and therapy, including C.S.F. cell counts $(\mathrm{L}=$ predominant lymphocytes, $\mathrm{P}=$ predominant polymorphs), titres of cryptococcal antigen and antibody, blood urea, and serum aspartate aminotransferase (SGOT), and periods of treatment with prednisone, blood urea, and serum aspartate aminotransferase (SGOT), and periods of treatment with prednisone,
amphotericin B (i.t. = intrathecal, i.v. = intravenous), and 5-fluorocytosine. In February 1969 the
serum antibody titre was $1 / 8$ and the C.S.F. was normal.

During this period of improvement he was found to have grossly reduced visual acuity in both eyes with large central scotomata; the fundi remained normal. After seven days he became pyrexial $\left(38.4^{\circ}\right.$ C. $)$, with headaches, vomiting, and neck stiffness. Lumbar puncture gave turbid cellular fluid under very high pressure. Direct smears of the C.S.F. showed a few degenerate fungi but culture for bacteria and fungi was negative. Because of the uncertainty about the cause of this acute meningitis treatment with chloramphenicol and penicillin was given for 10 days.

At this time a supply of 5 -fluorocytosine became available. He was treated with this drug in the recommended dose of $100 \mathrm{mg} . / \mathrm{kg}$. body weight/day and from then on symptomatic improvement was very rapid. After five days he was fully lucid and was able to sit out of bed for the first time. After a week's treatment there were only 10 lymphocytes per cu. $\mathrm{mm}$. in the C.S.F., the protein was $21 \mathrm{mg} . / 100 \mathrm{ml}$. and sugar $61 \mathrm{mg} . / 100 \mathrm{ml}$. He had no symptomatic side-effects from this drug, but there was a transient rise in the serum aspartate aminotransferase. After four weeks of treatment he was fully alert and had no symptoms or neurological signs except persistent central scotomata. 5-Fluorocytosine (6 g./day) was given for 43 days. Just before the end of the course the C.S.F. lymphocyte count increased, and three days after the drug was withdrawn there was a recurrence of headache and backache with a further deterioration in the C.S.F. findings (Fig. 1). 5-Fluorocytosine was given again in a dose of $9 \mathrm{~g}$. and then $12 \mathrm{~g}$. daily for a further
52 days together with prednisone $10 \mathrm{mg}$. daily. The symptoms were rapidly controlled and the C.S.F. returned virtually to normal. Five months after stopping treatment he remained well with normal C.S.F. and normal cryptococcal antibody and antigen titres, except for an antibody titre of $1 / 8$ in serum.

\section{Discussion}

The fluctuating depression, disorientation, and confusion seen in Case 1 are well-recognized features of cryptococcal meningitis, but it is unusual for them to continue for as long as a year without frank meningitic signs and especially without headache. It seems probable that the acute exacerbation of symptoms in which cryptococci were eventually isolated from the C.S.F. was precipitated by treatment with steroids. In the Mississippi Valley, where torulosis is endemic, hydrocortisone (100 mg. intravenously) is apparently used as a provocative test in cases of obscure chronic meningitis. Given 24 hours before lumbar puncture it may result in appearance of the organisms in the C.S.F. (P. Larson, personal communication, 1968). The subacute presentation in Case 2 was more typical, but it is of interest that despite the abundant cryptococci in the first two samples of C.S.F. the initial protein and sugar levels were normal.

The laboratory diagnosis of cryptococcal meningitis usually depends on the microscopical demonstration and culture of the organism (Fetter ct al., 1967). Case 1 illustrates how unreliable this may be. Until recently serological tests for the diagnosis of cryptococcosis have met with little success, but Bloomfield et al. (1963) described a method of sensitizing latex particles with globulins from rabbits injected with $C$. neoformans; these particles were then used in agglutination tests to detect the cryptococcal antigen in body fluids. Further experiences with this test were described by Gordon and Vedder (1966), who also showed that direct agglutination of suspensions of $C$. neoformans was an effective way of detecting antibody. These two tests were the ones used at the Mycological Reference Laboratory in the cases described above. More recently a combination of complement fixation and agglutination tests has been reported on favourably by Walter and Jones (1968). It is highly probable that the diagnosis would have been made earlier in Case 1 if these immunological tests had been used. We would suggest applying them in any case of obscure meningitis.

The introduction of treatment with amphotericin B reduced the mortality of cryptococcal meningitis from about $90 \%$ in the first year to $25 \%$ over three years (Williams, 1967). The drug must, however, be given intravenously in a dose which can rarely exceed $1 \mathrm{mg}$. $/ \mathrm{kg}$. body weight/day, until a total of $3 \mathrm{~g}$. has been given. In addition, during the active stages of the disease intrathecal administration $(0.025 \mathrm{mg}$. increasing to $0.5 \mathrm{mg}$. daily) is recommended. Even in these low dosages amphotericin B may have severe side-effects, the most important of which, apart from idiosyncratic reactions, is impaired renal function. This occurs in $80 \%$ of treated cases, though permanent renal damage can usually be prevented by reducing the dose (Williams, 1967). In Case 1 a full and successful course of 3 g. of amphotericin B was completed without serious complications. In Case 2, however, the drug gave rise to several wellrecognized and severe side-effects including renal failure, which 
necessitated withdrawal of the drug after only $350 \mathrm{mg}$. had been given. The blood urea returned to normal in a few days but the patient then developed an acute meningitis which was probably simply an exacerbation of the torulosis. Fortunately at this time a supply of 5 -fluorocytosine became available.<smiles>Nc1nc(=O)n(N)cc1F</smiles>

FIG. 2.-5-Fluorocytosine.

5-Fluorocytosine (Fig. 2) is not yet generally available in this country but has been tried in the treatment of cryptococcal meningitis in the U.S.A. (Grunberg et al., 1967). It is reported to be an antimetabolite of cytosine in C. neoformans, Candida albicans, and other fungi, but apparently not in man. It is effective in inhibiting the growth of these fungi but has apparently no antibacterial effect.

In man, after single oral doses of $2 \mathrm{~g}$. of 5 -fluorocytosine fungistatic concentrations persist in the blood for 6 to 10 hours. It is excreted unchanged in the urine. A single case of reversible pancytopenia after four weeks of treatment with 5-fluorocytosine was reported at secondhand by Tassel and Madoff (1968), and a transient rise in serum transaminases has occurred in one previous patient. In one patient with cryptococcal meningitis who failed to respond to amphotericin B $(\dot{3} \cdot 4 \mathrm{~g}$. intravenously over a period of three months) the symptoms improved and the C.S.F. became free from cryptococci after six weeks of treatment with 5-fluorocytosine. The C.S.F. concentration of the drug was almost equal to the blood level (I. Lenox-Smith, personal communication, 1968). Tassel and Madoff (1968) described a case resistant to amphotericin B, in which the patient responded to treatment with 5-fluorocytosine in a dose of $2.25 \mathrm{~g}$. daily for 50 days. In addition a number of patients with systemic candidiasis have apparently been successfully treated. The response to treatment in our own patient has been satisfactory, though it is too early to be certain of the prognosis in this disorder, in which the relapse rate is notoriously high. Because of the advantage of oral administration and its relative freedom from side-effects it may be, however, that 5-fluorocytosine will replace amphotericin B as the first choice in the treatment of cryptococcosis; certainly it merits further trials.

We are grateful to Professor J. N. Walton and Dr. K. Davison for permission to report these cases; and to Dr. I. Lenox-Smith, Dr. J. Garrod, and Roche Products Limited for generous supplies of 5-fluorocytosine and information about its use.

Requests for reprints should be sent to Dr. D. Gardner-Medwin at the Regional Neurological Centre, Newcastle General Hospital, Westgate Road, Newcastle upon Tyne NE4 6BE.

\section{REFERENCES}

Bloomfield, N., Gordon, M. A., and Elmendorf, D. F. (1963). Proceedings of the Society for Experimental Biology and Medicine, 114, 64 Fetter, B. F., Klintworth, G. K., and Hendry, W. S. (1967). Mycoses of the Central Nervous System. Baltimore, Williams and Wilkins.

Gordon, M. A., and Vedder, D. K. (1966). Fournal of the American Medical Association, 197, 961.

Grunberg, E., Prince, H. N., and Utz, J. P. (1967). In Proceedings of 5th International Congress of Chemotherapy, Vienna, vol. 4, edited by K. H. Spitzy and H. Haschek, p. 69. Vienna, Academy of Medicine. Tassel, D., and Madoff, M. A. (1968). Fournal of the American Medi-
cal Association, 206, 830.

Walter, J. E., and Jones, R. D. (1968). American Review of Respiratory Williams, T. W. (1967). Modern Treatment, 4, 951.

\section{Medical Memoranda}

\section{Bronchial Lavage in Status Asthmaticus}

British Medical fournal, 1969, 3, 31-32

Bronchial lavage as a treatment for severe status asthmaticus in adults was described by Broom (1960). More recently Ambiavagar and Jones (1967) described a regimen of management combining this with intermittent positive-pressure ventilation (I.P.P.V.). We report here the successful resuscitation of a moribund child by this technique, following mainly the recommendations of the latter two authors.

\section{CASE RePort}

The patient, a boy aged 14, had a history of asthma for five years and had been admitted to hospital for status asthmaticus eight months previously. He had then responded to a short course of steroids and had not since required any treatment. He was readmitted in status asthmaticus with a two-day history of respiratory infection and wheezing treated with choline theophyllinate (Choledyl) and orciprenaline (Alupent) inhalations. On the day of admission he had been given two injections of aminophylline intravenously.
On admission he was severely dyspnoeic but fully conscious. $\mathrm{He}$ had central cyanosis and pronounced inspiratory recession of the chest. His breath sounds were harsh and of poor intensity; there were no rhonchi. Blood pressure was 160/90. He was given intravenous hydrocortisone $100 \mathrm{mg}$., oral prednisone $10 \mathrm{mg}$., and $28 \%$ oxygen by Venturi facemask. Initially his colour improved, but an hour later he became cyanosed again, his state of consciousness deteriorated, and he developed signs of peripheral circulatory failure. At this stage his arterial blood showed $p \mathrm{H} 7 \cdot 1, \mathrm{PaCO}_{2}$ $105 \mathrm{~mm}$. $\mathrm{Hg}, \mathrm{PaO}_{2} 80 \mathrm{~mm}$. $\mathrm{Hg}$ (on $28 \%$ oxygen), and a base excess of $+2.5 \mathrm{mEq} / 1$.

After gastric aspiration and the intravenous infusion of $500 \mathrm{ml}$. of normal saline he was taken to the theatre and anaesthetized with halothane and ether in $100 \%$ oxygen. The trachea was intubated, and after a few minutes manual I.P.P.V. bronchial lavage was performed by instilling $10-\mathrm{ml}$. aliquots of $2.5 \%$ sodium bicarbonate down the endotracheal tube, each instillation being followed by aspiration of the chest helped by vibration and percussion. 'The patient was positioned so that each quadrant of the chest received the bicarbonate solution during instillation and was drained during aspiration and percussion. In between each positioning the lungs were inflated with $100 \%$ oxygen with some ether. The procedure took two hours in all. Bronchial casts (some of which are shown in the illustration) were aspirated, sufficient nearly to fill a $2-0 z$. (60-ml.) container. The patient tolerated the procedure well. $\mathrm{He}$ remained pink, his blood pressure and peripheral circulation improved, and at the end of the lavage his lungs were easier to inflate. 